\title{
The Effect of Osmium Staining on Lamellar Spacing in Thin Polystyrene-block- Polyisoprene Films
}

\author{
L. Staniewicz*, A. M. Donald*, D. J. Stokes** \\ * Department of Physics, University of Cambridge, Cavendish Laboratory, Cambridge, CB3 0HE, \\ UK \\ ** FEI Company, PO Box 80066, 5600KA, Eindhoven, The Netherlands
}

It has long been thought that differentiation between that low atomic number samples such as polymers requires staining with heavy elements such as lead or osmium to provide contrast in (scanning) transmission electron microscopy ((S)TEM). Such staining techniques are well established [1] and widespread amongst the polymer science community, but little work has been carried out as to whether staining alters the structure which it is intended to reveal.

Using a new transmission detector [2, 3] for the environmental scanning electron microscope (ESEM), we have been able to image thin films of polystyrene-polyisoprene block copolymer in their native state without resorting to staining. The detector itself is a two segment solid state device with integrated temperature control, used in an FEI XL30 ESEM-FEG.

Images showing contrast between the two phases in the same unstained sample have been successfully taken in a conventional TEM (FEI Tecnai 20), demonstrating that staining is not required even at high acceleration voltages. Contrast between the two phases appears to come from the difference in density between them $\left(1.04-1.065 \mathrm{~g} \mathrm{~cm}^{-3}\right.$ for amorphous polystyrene (PS) and $0.906-0.916 \mathrm{~g} \mathrm{~cm}^{-3}$ for amorphous polyisoprene (PI) [4]), as the chemical differences between them $\left(\mathrm{PS}=\left[\mathrm{C}_{8} \mathrm{H}_{8}\right]_{\mathrm{n}}, \mathrm{PI}=\left[\mathrm{C}_{5} \mathrm{H}_{8}\right]_{\mathrm{n}}\right)$ are negligible. Imaging of an unstained asymmetric PS-block-PI copolymer showed that the denser polystyrene scatters more strongly, giving rise to a stronger darkfield signal. The film itself was found by the colour of reflected light to be approximately $100 \mathrm{~nm}$ thick and the lamellae in the unstained sample are $113 \mathrm{~nm}$ across on average.

Staining the polymer film samples with osmium tetroxide vapour for one hour resulted in the stained phase (polyisoprene) swelling in the plane of the film by a factor of approximately 1.15, compressing the unstained phase (polystyrene) in-plane to a factor of 0.71 of its previous size in the process. This swelling is readily visible under the electron microscope, as Fig. 1 and 2 show. For comparison, images taken in the TEM are shown in Fig. 3 and 4. The contrast is almost as clear as with the much lower acceleration voltage $(\mathrm{TEM}=120 \mathrm{kV}, \mathrm{ESEM}=20 \mathrm{kV})$ used in the ESEMSTEM.

\section{References}

[1] L. C. Sawyer and D. T. Grubb, Polymer Microscopy, $1^{\text {st }}$ ed., Chapman and Hall, New York, 1987.

[2] A. Bogner et. al., Ultramicroscopy 104 (2005) 290-301.

[3] E. Doehne and E. Baken, Scanning 28 (Issue 2) (2006) 103-104.

[4] J. Brandrup et. al., Polymer Handbook, $4^{\text {th }}$ ed., John Wiley and Sons Inc., New York, 1999

[5] This work was supported by a grant from the Engineering and Physical Sciences Research 
Council, grant number EP/P50385X/1 and by a CASE studentship from FEI Company. The aid of Patrick Fairclough, Andrew Parnell, Nadejda Tzokova and Andrew Pryke from the University of Sheffield is greatly appreciated in providing the block copolymers used in this study, as well as that of FEI Company for providing the ESEM-STEM detector.

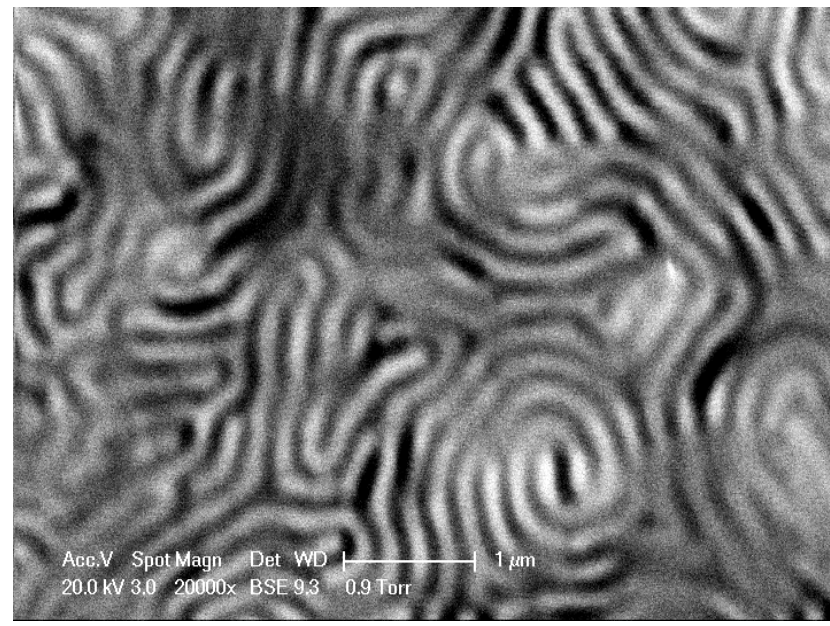

Fig. 1: A dark-field ESEM-STEM image of an unstained polystyrene-polyisoprene diblock copolymer film, taken at $20 \mathrm{kV}$ and with 1 Torr $(133 \mathrm{~Pa})$ of water vapour in the chamber to provide charge compensation. The light phase is polystyrene. The scale bar is $1 \mu \mathrm{m}$ long.

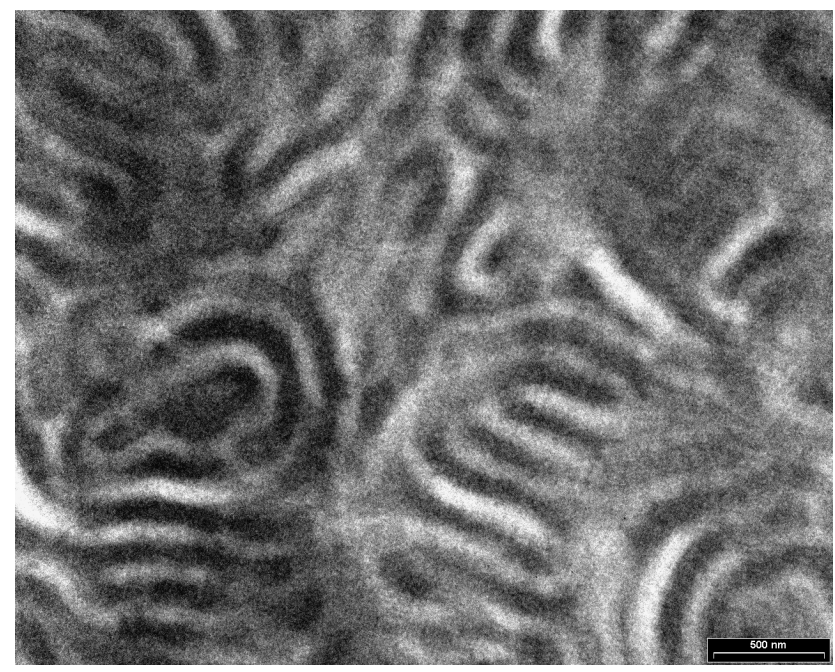

Fig. 3: A bright-field high-vacuum TEM image of an unstained polystyrene-polyisoprene diblock copolymer film, taken at $120 \mathrm{kV}$. The scale bar is $500 \mathrm{~nm}$ long. Contrast will be the reverse of that seen in Fig. 1, so the light phase will be the more weakly scattering polyisoprene.

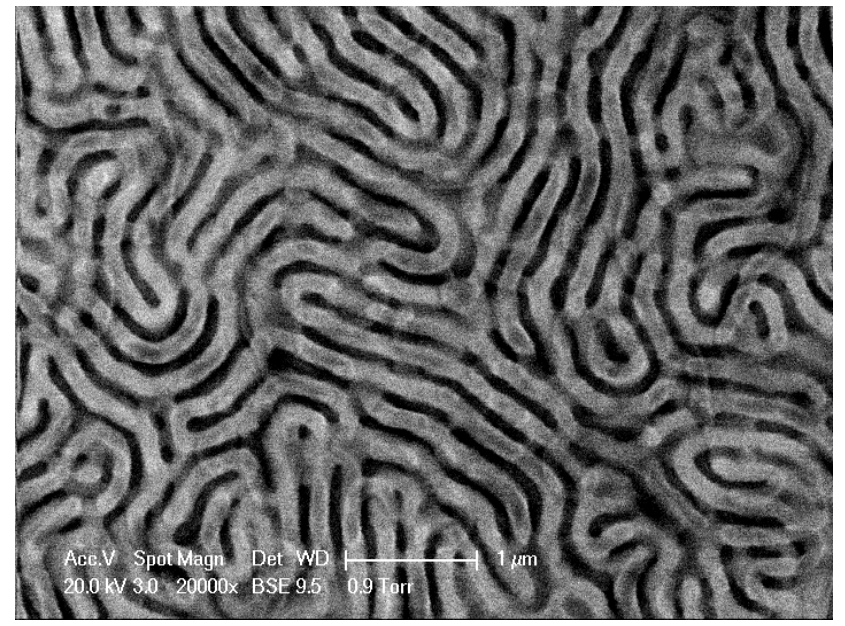

Fig. 2: A dark-field ESEM-STEM image of a stained polystyrene-polyisoprene diblock copolymer film, taken at $20 \mathrm{kV}$ and with 1 Torr (133 Pa) of water vapour in the chamber to provide charge compensation. The light phase is the stained polyisoprene (hence the contrast is reversed from Fig. 1). The scale bar is $1 \mu \mathrm{m}$ long.

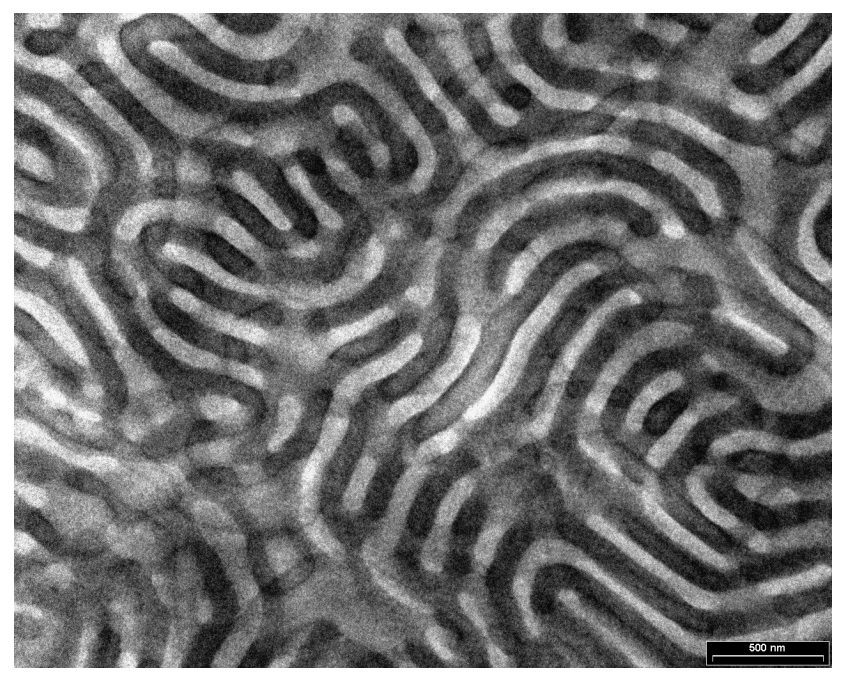

Fig. 4: A bright-field high-vacuum TEM image of a stained polystyrene-polyisoprene diblock copolymer film, taken at $120 \mathrm{kV}$. The scale bar is 500nm long. Just as in Fig. 3, the contrast in this image will be reversed with respect to its ESEM-STEM counterpart (Fig. 2) 